\title{
ETHICAL DILEMMAS IN FORENSIC MEDICAL PRACTICE
}

\section{Kitulwatte I.D.G. \& Edirisinghe P.A.S.}

\author{
Department of Forensic Medicine, Faculty of Medicine, Ragama, Sri Lanka \\ Corresponding Author: Kitulwatte I.D.G.
}

Email: indiradgk@yahoo.com

https: / / orcid.org / 0000-0002-6108-9059

\begin{abstract}
Forensic practitioners need to ensure that basic medical obligations towards individual patients, judiciary and the public are met while balancing their responsibilities to these parties. Unlike in clinical practice the patient does not present for treatment but for forensic evaluation. Even so, medical practitioners are expected to ensure that ethical standards like for any other medical discipline are maintained in medicolegal practice.

At a forensic medical examination, there is an obligation to act in the best interest of the patient and to attend to his/her critical needs. However, attending to the needs of the patient may be viewed as taking undue interest or being fractional by the judiciary. On the other hand, in medical practice, responsibility to patients should overide the interests of third parties.
\end{abstract}

In examination of the dead for medico-legal purposes, the question that can arise is whether there is actually a doctor patient relationship since the examinee is already dead. While there is a duty towards the judiciary to find out the truth about the cause and manner of death there is a duty towards the relatives of the deceased to reveal the true findings especially after having contact with them at the preliminary inquiry.

Many of the conclusions made in forensic practice are matters of opinion, and therefore, disagreement is expected which can lead to personal friction specially in handling cases of medical negligence. If forensic practitioners follow the basic principles of medical ethics, while maintaining the highest standards based on scientific evidence they can overcome the majority of the conflicting issues and can perform their duty in the administration of justice.

Key words: ethics, forensic medicine and pathology, best interest, doctor patient relationship, judiciary

All articles in Sri Lanka Journal of Forensic Medicine, Science \& Law are licensed under the terms of the Creative Commons Attribution-Non Commercial 4.0 International License. 


\section{ETHICAL DILEMMAS IN FORENSIC} MEDICAL PRACTICE

Forensic medicine is the application of principles and practice of medicine to aid the administration of justice. Thus, a forensic examiner will use his/her knowledge in medicine, to interpret the findings and to come to conclusions and opinion to exercise expert judgement. In both clinical and pathological forensic medical practice, basic ethical principles relevant to practice of clinical medicine such as autonomy (rights of the patient to make decisions), beneficence (obligation to act in the best interest of the patient), non maleficence (obligation to do no harm to the patient), and justice (fairness and giving what is rightfully due) has to be maintained in every instance. ${ }^{1}$ Doctors practicing forensic medicine are first and foremost medical practitioners and are therefore subject to all other codes of ethics and behaviour that govern medical practice. Further, forensic practitioners should ensure that basic medical obligations towards individual patients, the justice system (Courts) and the general public are met. Therefore, it is necessary to balance their responsibilities to all these parties. Being aware of possible conflicts of interest between these three groups is essential in the forensic context.

The doctor patient relationship in a clinical encounter is fundamentally a moral activity that arises from the necessity to care for patients and to alleviate suffering ${ }^{2,3}$ This relationship exists when a physician attends to medical needs of a patient with a mutual agreement or consent. However, on rare occasions treatment may be provided under a court order in clinical practice. ${ }^{4}$ Even then the doctor's responsibility to the patient remains intact. In any kind of doctor patient relationship doctors are bound by ethical obligations, placing patients' welfare above self-interest and obligations to other groups. $^{5}$
Autonomy, the duty of doctors to respect the freedom of patients to make decisions for themselves concerning how they want their body to be treated and whether, and to whom, information about them is to be disclosed exists in forensic medical practice as well. It is a general legal and ethical standard that valid consent must be obtained before commencing treatment or conducting physical examination of a patient. ${ }^{6}$ It is the patient's right to determine what happens to their own bodies. Even in therapeutic medicine, when patients are brought by a court order, no procedure can be initiated without mutual agreement between the patient and the physician. ${ }^{7}$ The same principle is applicable in forensic medical practice. In obtaining consent, the forensic practitioner must make clear to the examinee the purpose and the nature of the examination. In addition, the consent must be freely given and the examinee must be aware that there is no obligation to provide consent. Furthermore, it is important to inform such patients that forensic examinations are performed to obtain information which may ultimately be used as evidence in court proceedings against him.

When discharging their duties, forensic practitioners may face situations with conflicts of interest. Unlike in clinical practice, the patient does not present for treatment but for forensic evaluation. ${ }^{8}$ Even so the public would expect the same ethical standards like that of any other medical profession in general. The forensic practitioner may be the first and only physician who evaluates a patient with critical needs. Therefore, there is an obligation on the part of the practitioner to act in the best interest of the patient or to attend to his critical needs.

The ethical principle beneficence, recognizes the duty of doctors to do good for their patients and everyone must be provided with access to health care and emergency medical treatment. ${ }^{9}$ For 
example, there can be a victim of sexual abuse, who needs emergency contraceptives to prevent unwanted pregnancy and post exposure prophylaxis for HIV. However, the main obligation expected from a forensic medical practitioner is to assist the courts in the administration of justice. Presenting the evidence fairly and objectively without being supportive to a particular party or maintaining impartiality is expected in this exercise. ${ }^{1}$ Attending to the needs of the victim, may be viewed as taking undue interest or being prejudiced by the judiciary. On the other hand, as this is a medical profession, failure to attend to the critical needs of the patient after recognizing them would lead to an act of negligence. When faced with dual loyalty conflicts such as this, forensic practitioners should act in the best interest of the patient first.

The principle of non-maleficence states that doctors should prevent harm that could occur to the body, mind or reputation of the patient. ${ }^{10}$ Information obtained in the doctor patient relationship is expected to be confidential. This customary therapeutic agreement and assurances of confidentiality do not exist in a forensic context. ${ }^{11}$ Forensic practitioners are bound by the legal obligations to divulge information. Therefore, the limit of confidentiality has to be informed at the outset of the evaluation. Further, forensic pathologists should treat bodies with dignity, and the confidentiality of persons should be maintained even after death especially in situations where stigmata are attached, unless the finding is something, which is relevant in the courts.

Victims and alleged perpetrators of crimes should be treated equally according to the basic ethical principle of justice. ${ }^{11}$ Priority must be given to the clinical needs of the patient irrespective of being a victim or perpetrator. In a case of torture of a detainee who may be a threat to society, forensic practitioners should first attend to his medical needs and issue a report on torture without being partial or biased. On the other hand, there can be a situation where the forensic practitioner discovers that the patient who presented with blast injuries in his hands is a bomb handler. This may be an instance where duty towards society should supersede the patient's best interest. Still it is the responsibility of the forensic practitioner to inform the patient regarding the limitation of confidentiality.

Maintaining good professional relationships with colleagues is the expected ethical standards from a physician. ${ }^{12}$ However, many of the conclusions made in forensic practice are matters of opinion and therefore, disagreement is expected which can lead to conflicts between experts. Forensic practitioners may discover mistakes of colleagues in their forensic evaluation. They are expected to be truthful and should allude to these mistakes in the report. However caution needs to be exercised in making comments and formulating an opinion with scientific reasoning. Forensic practitioners are not familiar with the specialties of medicine which are rapidly advancing. Therefore, it is important that a forensic practitioner recognises the limits of their expertise and provide balanced opinion based on scientific interpretations while limiting to his/her expertise. In addition, if the opinion is based on scientific evidence and directed towards justice without partiality towards an interested party, the disagreement, which is expected, can be minimized.

When forensic pathology is considered, the main question that can arise is whether there actually is a doctor patient relationship. The answer can be unclear since the subject is deceased. It is worthwhile to consider to whom a forensic pathologist owes a duty to. It is the general understanding that a forensic pathologist owes a duty to the memory or reputation of the deceased as requested by the courts to find out the truth about the cause and manner of death. Further, there is a duty towards the 
community including the relatives of the deceased. Therefore, it is of utmost importance to reveal the true findings to the community, especially the relatives. One may argue that forensic pathologists act under the authority of the courts and therefore owe a duty only to the judiciary. Indeed, divulging true findings to the courts is definitely an obligation. However, after communicating with relatives of the deceased prior to autopsy, it is of equal importance to maintain the expected reputation of honesty and integrity with them by divulging the true facts while being cautious in making opinions.

The forensic medical profession must strive to preserve the trust patients hold in them while appreciating the responsibility they owe to the criminal justice system and to the public. Ethical standards cannot be abandoned simply because the relationship with the patient is not for alleviation of suffering. As the main obligation of a forensic medical practitioner is to assist the judiciary in determining the truth while protecting the patient from incompetent or illegal practices by others, he or she must always preserve integrity, truthfulness and exhibit competence at all times while abiding by the code of ethics and behavior that governs the medical profession.

\section{REFERENCES}

1. M.M. El-Nageh, Ethical practice in Laboratory Medicine and Forensic Pathology, WHO Regional Publication, Eastern Mediterranean Series, 1999: Volume 20; 29-41.

2. Baker RB, Caplan AL, Emanuel LL, Latham SR, eds. Baltimore. The American Medical Ethics Revolution: Johns Hopkins University Press; 1999: 17-51.

3. Bell J. Introduction to the 1847 Code of Ethics (Appednix B) In: The American Medical Ethics Revolution. Baker RB, Caplan AL, Emanuel LL, Latham SR, eds.
Baltimore, Md: Johns Hopkins University Press; 1999:317-323.

4. Katsakou C, Priebe S "Outcomes of involuntary hospital admission-a review". Acta Psychiatr Scand. 2006:114 (4): 23241.

5. I. Glenn Cohen, Holly Fernandez Lynch, and Christopher R. Deubert. A Proposal to Address NFL Club Doctors' Conflicts of Interest and to Promote Player Trust. Hastings Cent Rep. 2016; 46(Suppl Suppl 2): S2-S24.

6. Atyanarayana Rao KH. Informed consent: An ethical obligation or legal compulsion? J Cutan Aesthet Surg. 2008;1:33-5.

7. Arne Hantho, Lena Jensen \& Kirsti Malterud Mutual understanding: a communication model for general practice, Scandinavian Journal of Primary Health Care, (2002) 20:4,244-251, DOI: 10.1080/ 028134302321004926 .

8. Greenberg, S., \& Shuman, D. Irreconcilable conflict between therapeutic and forensic roles. Professional Psychology: Research and Practice. 1997: 28; 50-57.

9. Ramesh P Aacharya, Chris Gastmans and Yvonne Denier. Emergency department triage: an ethical analysis. BMC Emergency Medicine 2011,11:16. http://www. biomedcentral.com/1471-227X/11/16.

10. Warren T. Jahn, DC, MPS. The 4 basic ethical principles that apply to forensic activities are respect for autonomy, beneficence, nonmaleficence, and justice. $\mathrm{J}$ Chiropr Med. 2011; 10(3): 225-226. doi: 10.1016/j.jcm.2011.08.004.

11. Karen C. Kalmbach, Phillip M. Lyons. Ethical Issues In Conducting Forensic Evaluations; Unique Nature of Forensic Mental Health Practice. Applied Psychology in Criminal Justice. 2006: 2(3); 261-189.

12. Guidebook for managing disruptive physician behavior. College of Physicians and Surgeons of Ontario 